\section{A Vacuum Core-Sampler for Deep-Sea Sediments}

Few geophysical problems have such important bearings as that of sampling undisturbed sediment cores of great length from ocean deeps. Questions pertaining to the permanence of ocean basins or their subsidence, to continental drift, to climatic changes and to variations in volcanic activity, etc., can best be answered through studies of the stratigraphy of deep-sea sediments, sampled in the manner just indicated. Recently, Dr. Piggot of the Carnegie Institution of Washington has obtained cores from the north-west Atlantic bottom approaching $3 \mathrm{~m}$. in length, by projecting the sampler into the sediment by means of an explosive charge.

According to a scheme advanced by one of us at the meeting of the International Council in 1933, the hydrostatic pressure prevailing at great depths has been utilized for forcing a tube-sampler down into the sediment. The first instrument, constructed during last summer in the workshop of this Institute and put to practical tests in the fall of the same year, consisted of a $2 \mathrm{~m}$. length of steel tubing, $2 \mathrm{in}$. wide, closed at its upper end and having a water-tight piston at its lower end, released by trigger action as soon as it touched the sediment surface. The air was pumped out of the tube before immersion, so that the piston, followed by a column of sediment, was able to move up to the upper end without com. pressing any air behind it, which might otherwise expand and push out the core on hauling up the sampler to the surface. The tests made with this first sampler proved the release to function well, and the tube was filled with sediment; but at depths exceeding $150 \mathrm{~m}$. the shock due to the impact from the piston proved too severe for the steel bolts securing the lid to the upper end of the tube. Moreover, the looser kinds of sediments were sucked into the tube, before it had time to descend completely into the sediment.

A modified instrument was accordingly constructed with a cylindrical container of much wider bore attached to the upper end of the tube. The container is evacuated, whereas the tube itself is completely filled with water which, after the release, is free to enter the container through a nozzle of a more or less narrow bore, according to the depth in which the sample is to be taken. Thus the rate at which the tube sinks into the sediment can be made practically equal to the rate at which the sediment core mounts into the tube. Tests with this new sampler made at depths down to $240 \mathrm{~m}$. have been entirely successful, cores of lengths - varying between $160 \mathrm{~cm}$. and $200 \mathrm{~cm}$. being readily obtained. Markings on the outside of the tube proved the sampler to have sunk,into the sediment to a depth agreeing to within a few centimetres with the length of the core. A deep-sea sampler with a larger spherical container and a tube 6 metres in length is now being constructed and gives hope of obtaining cores of approximately the same length from depths of $4,000 \mathrm{~m}$. or more.

With all types of samplers hitherto used, including that of Dr. Piggot, the friction against the inside of the tube prevents cores of equal length to the depth of immersion in the sediment being sampled (see Pratje's recent experiences in the Baltic). With the vacuum sampler this friction is counteracted by suction, properly regulated, so that the core will give a true picture of the undisturbed stratification of the sediment. Moreover, since the force pressing the tube down into the sediment increases with the bore of the tubs, and with the depth of water, it should be possible to obtain cores of still greater thickness and length, say $10 \mathrm{~m}$. if not even more, by means of this sampler. The instrument will be described in greater detail in a coming issue of Meddelanden fran Oceanografiska Institutet $i$ Göteborg.

Hans Pettersson. BörJe KUllenberG.

Oceanografiska Institutet, Stigbergstorget, 8, Göteborg, 4.

${ }^{1}$ Ann. Hydroyraphie, 213 (1939).

\section{The $\alpha, \beta$ Transformation of Quartz}

Sir C. V. Raman and T. M. K. Nedungadi have discussed in NATURE of January 27 a remarkable series of photographs showing the spectrum of monochromatic light scattered in a quartz crystal at various temperatures up to $530^{\circ} \mathrm{C}$., not far from the transition point at $575^{\circ} \mathrm{C}$. Their results are of special interest to me because they serve to confirm my opinion that, at any transition temperature (including the melting point), some kind of resonance occurs between two frequencies which characterize the two phases concerned. In other words, the transition takes place when there is close agreement between a frequency characteristic of the first phase and another frequency characteristic of the second phase. Since resonance may occur when this agreement is not quite exact, an explanation is possible of the fact that for many substances the 'setting' point is not quite the same as the 'fusion' point.

In the experiments on quartz, the authors state that "the $220 \mathrm{~cm}^{-1}$ line behaves in an exceptional way, spreading out greatly towards the exciting line and becoming a weak diffuse band as the transition temperature is approached. On the other hand, the other intense lines [including 132 and $468 \mathrm{~cm}^{-1}$ ] having both larger and smaller frequency shifts continue to be easily visible, though appreciably broadened and displaced". They infer that the binding forces corresponding to the line $220 \mathrm{~cm}^{-1}$ diminish rapidly with rising temperature, and also that the increasing excitation of this particular mode of vibration and the resulting deformation of the atomic arrangement are in a special measure responsible for the changes in the physical properties of the crystal, as well as for inducing the transformation from the $\alpha$ to the $\beta$ form.

So far as I am aware, there is no information available as to the characteristic frequency of $\beta$-quartz save that which is obtainable from the Sutherland. Lindemann formula

$$
v=\frac{3 \cdot 08 \times 10^{12}}{V^{1 / 3}} \sqrt{\frac{T}{M}}
$$

where $T$ is the absolute temperature of the melting point, $M$ is the molecular weight, and $V$ is the molecular volume. Assuming that $T$ is $2,053^{\circ} \mathrm{K}$., and the density is $\mathbf{2 \cdot 6 5}$, the calculated frequency is $3.63 \times 10^{12}$ sec. $^{-1}$, corresponding to $212 \mathrm{~cm}^{-1}$, and thus supports the hypothesis put forward. 